\title{
An engineered micropattern to reduce bacterial colonization, platelet adhesion and fibrin sheath formation for improved biocompatibility of central venous catheters
}

Rhea M May ${ }^{1}$, Chelsea M Magin ${ }^{1}$, Ethan E Mann ${ }^{1}$, Michael C Drinker ${ }^{1}$, John C Fraser ${ }^{1}$, Christopher A Siedlecki ${ }^{2}$, Anthony B Brennan ${ }^{3}$ and Shravanthi T Reddy ${ }^{1 *}$

\begin{abstract}
Background: Catheter-related bloodstream infections (CRBSIs) and catheter-related thrombosis (CRT) are common complications of central venous catheters (CVC), which are used to monitor patient health and deliver medications. CVCs are subject to protein adsorption and platelet adhesion as well as colonization by the natural skin flora (i.e. Staphylococcus aureus and Staphylococcus epidermidis). Antimicrobial and antithrombotic drugs can prevent infections and thrombosis-related complications, but have associated resistance and safety risks. Surface topographies have shown promise in limiting platelet and bacterial adhesion, so it was hypothesized that an engineered Sharklet micropattern, inspired by shark-skin, may provide a combined approach as it has wide reaching anti-fouling capabilities. To assess the feasibility for this micropattern to improve CVC-related healthcare outcomes, bacterial colonization and platelet interactions were analyzed in vitro on a material common for vascular access devices.
\end{abstract}

Methods: To evaluate bacterial inhibition after simulated vascular exposure, micropatterned thermoplastic polyurethane surfaces were preconditioned with blood proteins in vitro then subjected to a bacterial challenge for 1 and $18 \mathrm{~h}$. Platelet adhesion was assessed with fluorescent microscopy after incubation of the surfaces with platelet-rich plasma (PRP) supplemented with calcium. Platelet activation was further assessed by monitoring fibrin formation with fluorescent microscopy after exposure of the surfaces to platelet-rich plasma (PRP) supplemented with calcium in a flow-cell. Results are reported as percent reductions and significance is based on $t$-tests and ANOVA models of log reductions. All experiments were replicated at least three times.

Results: Blood and serum conditioned micropatterned surfaces reduced $18 \mathrm{~h}$ S. aureus and S. epidermidis colonization by $70 \%(p \leq 0.05)$ and $71 \%(p<0.01)$, respectively, when compared to preconditioned unpatterned controls. Additionally, platelet adhesion and fibrin sheath formation were reduced by $86 \%$ and $80 \%(p<0.05)$, respectively, on the micropattern, when compared to controls.

Conclusions: The Sharklet micropattern, in a CVC-relevant thermoplastic polyurethane, significantly reduced bacterial colonization and relevant platelet interactions after simulated vascular exposure. These results suggest that the incorporation of the Sharklet micropattern on the surface of a CVC may inhibit the initial events that lead to CRBSI and CRT.

Keywords: Sharklet; Microtopography; Platelet activation; Blood compatibility; Infection; CRT; CRBSI

\footnotetext{
* Correspondence: sreddy@sharklet.com

${ }^{1}$ Sharklet Technologies, Inc, 12635 E. Montview Blvd. Suite 155, Aurora CO 80045, CO, USA

Full list of author information is available at the end of the article
} 


\section{Background}

Approximately six million central venous catheters (CVCs) are inserted each year in the U.S. [1] to provide efficient vascular monitoring and medication delivery. Thermoplastic polyurethane (TPU) has been adopted as the material of choice for CVCs due to its workability, resiliency and improved blood compatibility over other plastics [2]. CVC design improvements, such as valves and cuffs, have been introduced to prevent tube occlusion and limit microbial access to the bloodstream. Unfortunately even with these improvements, CVCs lead to the downstream complications of catheter-related blood stream infections (CRBSIs) and thrombosis (CRT), which are associated with increased mortality $[3,4]$.

CRBSIs are primarily caused by the patient's skin flora (e.g. Staphylococcus aureus, S. epidermidis, Candida spp.) that colonize the device and enter the blood stream [5]. Education for personnel who insert catheters, use of sterile barrier precautions, and chlorhexidine skin antisepsis during insertion have helped to reduce, but not eliminate, CRBSI rates $[1,6,7]$. Antimicrobial catheters also show promise in reducing CRBSI rates [8]. However, studies show that these catheters harbor microorganisms [9] and this constant exposure contributes to the rise in antimicrobial resistance among pathogens $[10,11]$.

Factors that lead to thrombus formation and subsequent CRT involve a complex series of events beginning with the deposition of a variety of blood proteins and tissue factors that together facilitate platelet adhesion to a surface $[12,13]$. Platelets then activate and expedite the coagulation cascade, frequently leading to fibrin sheath formation along the device within $24 \mathrm{~h}$ [14]. Routine anticoagulation prophylaxis, blood-thinning therapy, and flushing of catheter ports, typically with heparin, are the only methods currently used to prevent CRT. Unfortunately, these treatments have not demonstrated efficacy against morbidity and mortality $[14,15]$ and can lead to thrombocytopenia, where low platelet counts in the blood can cause hemorrhaging or an increased risk of CRT [16,17].

Several studies indicate that infection and thrombosis are clinically linked where patients with CRBSI often acquire CRT, and vice versa [18-23]. Controlled in vivo and in vitro studies have demonstrated that fibrin sheath on catheters increase bacterial colonization and correlate with positive blood cultures [24-27]. Alternatively, many bacterial strains, in addition to coagulase-positive $S$. aureus, can initiate the coagulation cascade resulting in fibrin clot formation $[28,29]$. These studies suggest that bacterial attachment or fibrin sheath formation on the surface of CVCs could be an underlying mechanism behind this strong clinical correlation.
Incorporation of nano and micropatterns into CVC surfaces has been proposed to reduce CRBSI and CRT rates without antimicrobial or antithrombogenic coatings. Specifically, ordered pillar topographies, with dimensions of $300 \mathrm{~nm}$ to $1 \mu \mathrm{m}$, have been shown to reduce platelet adhesion and aggregation [30,31]. The Sharklet micropattern, either with recessed $(-3 \mathrm{SK} 2 \times 2)$ or protruding $(+3 \mathrm{SK} 2 \times 2)$ features on the same size scale (i.e. $2 \mu \mathrm{m}$ to $16 \mu \mathrm{m}$ ) contains an ordered arrangement of features bio-inspired by the diamond-like structure of shark skin. Sharklet micropatterns have been shown to control the bioadhesion of a wide range of marine microorganisms, pathogenic bacteria and eukaryotic cells [32-37]. The aim of the present study is to expand our understanding of the performance of the Sharklet micropattern against common microorganisms that cause CRBSIs after blood protein exposure as well as platelet adhesion and activation that leads to fibrin sheath formation and CRT.

\section{Methods \\ Sample fabrication}

Thermoplastic polyurethane (TPU) samples, with and without the Sharklet micropattern, were created by thermal embossing. Briefly, Tecoflex EG-85A pellets (Lubrizol) were heated and pressed in a Carver hydraulic press at $185^{\circ} \mathrm{C}$ and $40 \mathrm{MPa}$ for $10 \mathrm{~min}$ to create a blank film. The resulting film was then embossed against a patterned or polished (smooth, unpatterned) nickel mold [34] to a thickness of $\sim 0.4 \mathrm{~mm}$ in a Carver hydraulic press at $185^{\circ} \mathrm{C}$ and $40 \mathrm{MPa}$ for an additional $2 \mathrm{~min}$. Each flat $0.4 \mathrm{~mm}$ thick film was either punched into $12 \mathrm{~mm}$ diameter circular coupons or cut into $75 \times 25 \mathrm{~mm}$ rectangles. The micropatterns produced by this technique were comprised of discontinuous channel features arranged in a Sharklet micropattern that either protruded $(+)$ from or were recessed (-) into the polymer surface with features $3 \mu \mathrm{m}$ tall or deep that were $2 \mu \mathrm{m}$ wide and spaced by $2 \mu \mathrm{m}$; referred to throughout this study as +3 SK $2 \times 2$ and -3 SK $2 \times 2$ (Figure 1).

\section{Microbial strains, media, and growth conditions}

Clinical isolates of S. aureus (ATCC 6538) and S. epidermidis (ATCC 35984) were analyzed in this study. A single colony of each bacterial strain, plated on tryptic soy agar (TSA; Criterion), was used to inoculate tryptic soy broth (TSB; Criterion) and grown in a shaking incubator at $37^{\circ} \mathrm{C}$ and $280 \mathrm{rpm}$ overnight. Overnight microbial cultures were sub-cultured and grown to early $\log$ phase in TSB before centrifuging aliquots and resuspending cell pellets with $1 \times$ phosphate buffered saline (PBS; CulGeneX) to the desired inoculum concentration based on a previously-established ratio of optical density and $\mathrm{CFU} / \mathrm{ml}$. 


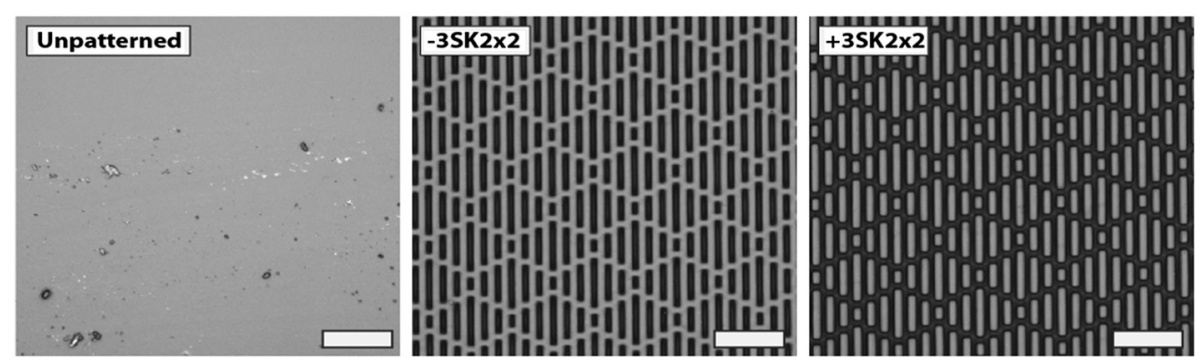

Figure 1 Confocal microscopy images of a) unpatterned controls b)-3SK2 $\times 2$ and c) +3 SK2 $\times 2$ Sharklet micropatterns replicated in TPU. Representative images of the surfaces analyzed in this study. Scale bar, $20 \mu \mathrm{m}$.

\section{Staphylococcal colonization post blood protein pre-treatment}

Bacterial aggregation, cell death, and clotting occurs when simultaneously incubating blood with $S$. aureus [38-42]. For in vitro studies, methods for surface pre-conditioning with blood or $25 \%$ serum, the physiologically relevant serum concentration found in blood, prior to bacterial inoculation were selected based on several published studies investigating the in vitro effects of blood-bacteria interactions for CVC applications [43-45]. Two agitation states were investigated as a CVC is subjected to a range of shear forces from static environments inside the lumen to flow rates of $17-81 \mathrm{ml} / \mathrm{min}$ in the blood vessel, depending on the tube size [46]. Micropatterned and unpatterned $12 \mathrm{~mm}$ TPU coupons $(\mathrm{n}=4)$ were pressed to the bottom of a sterile Petri dish around the outer perimeter. Coupons were immersed in either citrate-treated whole blood (Bonfils Blood Bank) or 25\% serum in PBS (Interstate Blood Bank) for $2 \mathrm{~h}$ at $37^{\circ} \mathrm{C}$ either statically or dynamically (30 rpm) to match the inoculation condition. The pretreatment media was rinsed three times by adding $20 \mathrm{ml}$ of sterile PBS to the dish, swirling ( $80 \mathrm{rpm})$ for $30 \mathrm{~s}$ on an orbital shaker, and decanting the rinsate. Surfaces were then immersed in $20 \mathrm{ml}$ of inoculum containing $\sim 10^{7}$ (static) or $\sim 10^{8}$ (dynamic) CFU/ml of either S. aureus or S. epidermidis and statically or dynamically incubated for 1 and $18 \mathrm{~h}$ at $37^{\circ} \mathrm{C}$. After incubation, the inoculum suspension was decanted, surfaces were rinsed three times identically as washing following pre-treatment, punched with an $8 \mathrm{~mm}$ biopsy punch, vortexed and sonicated as described above. Bacterial eluate solutions were enumerated by a 10-fold dilution series, plating each dilution onto TSA, and counting the colony forming units (CFU) after sufficient growth at $37^{\circ} \mathrm{C}$ overnight. Each CFU per surface data point was $\log _{10}$ transformed before statistical analysis. Each experiment was replicated three times. Fluorescent microscopy was used to qualitatively verify the $18 \mathrm{~h} \mathrm{CFU}$ results by fixing with $4 \%$ paraformaldehyde and staining with $\mathrm{TOTO}^{\circ}$-3. Images were obtained in three preselected sites per surface by confocal laser scanning microscopy (Zeiss LSM 510 META on Axiovert 200 M).

\section{Platelet adhesion}

Micropatterned and unpatterned $12 \mathrm{~mm}$ TPU coupons $(n=3)$ were pressed to the bottom of a sterile Petri dish around the outer perimeter. Surfaces were immersed in $20 \mathrm{ml}$ of a final concentration of $\sim 10^{6}$ platelets $/ \mu \mathrm{l}$ derived from platelet rich plasma (Bonfils Blood Bank) diluted with PBS supplemented with $10 \mathrm{mM}$ calcium chloride for $2 \mathrm{~h} 37^{\circ} \mathrm{C}$ while rotating at $80 \mathrm{rpm}$. Surfaces were rinsed three times by adding PBS to the dish, rotating $(80 \mathrm{rpm})$ for $30 \mathrm{~s}$ on an orbital shaker, and decanting the rinsate. Platelets were fixed on surfaces for $1 \mathrm{~h}$ in $1 \%$ paraformaldehyde at room temperature. Fixed surfaces were blocked with 10\% normal goat serum (Invitrogen) for $1 \mathrm{~h}$ before applying a primary $\alpha_{\text {IIb }} \beta_{3}$ integrin antibody (ab662, abcam) diluted 1:1000 in $10 \%$ normal goat serum (Invitrogen) and incubating overnight at $4^{\circ} \mathrm{C}$. Surfaces were exchange rinsed with PBS five times before adding secondary Alexa-Fluor555 IgG antibody (Invitrogen) diluted 1:100 in 6\% normal goat serum for $1 \mathrm{~h}$ at room temperature. Images were taken in 10 pre-determined locations per sample by fluorescent microscopy (Zeiss LSM 510 META on Axiovert $200 \mathrm{M})$, area coverage $\left(\mu \mathrm{m}^{2}\right)$ was measured using ImageJ, and each coverage data point was log transformed prior to statistical analysis. Each experiment was replicated four times.

\section{Fibrin sheath formation}

Micropatterned and unpatterned $75 \times 25 \mathrm{~mm}$ TPU samples were loaded into a two-chamber flow cell and exposed to a final concentration of $\sim 10^{5}$ platelets $/ \mu \mathrm{l}$ derived from platelet rich plasma (Bonfils Blood Bank) diluted in PBS supplemented with $5 \mathrm{mM}$ calcium chloride at a physiologically relevant flow rate of $100 \mathrm{~s}^{-1}$ for $1 \mathrm{~h}$ at $37^{\circ} \mathrm{C}$. Surfaces were rinsed in PBS and fixed with $1 \%$ paraformaldehyde for $1 \mathrm{~h}$ at room temperature. Two $14 \mathrm{~mm}$ circular samples were cut from each surface and blocked with $5 \%$ goat serum for $1 \mathrm{~h}$ prior to staining for fibrinogen with a goat polyclonal primary antibody (ab6666, abcam) for $1 \mathrm{~h}$ at room temperature. The primary antibody solution was then exchanged with $5 \%$ 
goat serum, and surfaces were counterstained with a secondary Alexa-Fluor 647 IgG antibody (ab150131, abcam) in $6 \%$ goat serum for $1 \mathrm{~h}$. Images were taken in nine pre-determined locations per surface by fluorescent microscopy (Olympus BX3-CBH), area coverage $\left(\mu \mathrm{m}^{2}\right)$ was measured using ImageJ, and each coverage data point was $\log$ transformed prior to statistical analysis. Each experiment was replicated three times.

\section{Statistical analysis}

A $\log$ reduction (LR) per experiment was calculated by subtracting the average of the $\log _{10}$ transformed values from micropatterned surfaces from the average of the $\log _{10}$ transformed values from unpatterned surfaces. After confirming the normality of the log reductions by residual and normal probability plots, the mean log reduction was interpreted as the median percent reduction with the equation: $1-10^{(-\mathrm{LR})}$. Statistical significance of the reductions were assessed using a 1-sided $t$-test of log reductions compared to zero. Estimates of variances and Tukey tests were assessed using an ANOVA model of the log transformed data for each unpatterned control sample and micropatterned sample, with a random effect for experiment [47]. All analyses were performed using the statistical software MiniTab16.

\section{Results}

\section{Staphylococcal colonization post blood protein pre- treatment}

In the range of environments selected to model the clinical environment, the $-3 S K 2 \times 2$ TPU surfaces demonstrated significant reductions of $S$. aureus colonization ranging from $63 \%$ to $70 \%$ compared to unpatterned TPU controls, after whole blood pre-conditioning under dynamic and static conditions (Table 1). The ability of the Sharklet micropattern to reduce $S$. aureus colonization was independent of the presence of flow, incubation time and pre-treatment media, based on a Tukey simultaneous test to evaluate significant differences among log reductions (Table 1). S. epidermidis attachment to challenge TPU surfaces was below the level of CFU detection when evaluated after whole blood pre-conditioning or under dynamic conditions, similar to previous observations [48]. Thus, 25\% serum pre-treatment (a physiologically relevant concentration of blood proteins) with static incubation was the only condition that could be quantitatively evaluated (Table 1).-3SK $2 \times 2$ TPU surfaces demonstrated reductions of $S$. epidermidis colonization after $18 \mathrm{~h}$ by at least $71 \%(p<0.01)$ when compared to unpatterned TPU controls under both saline and serum pre-conditioning (Table 1). The capability of the Sharklet micropattern to reduce $S$. epidermidis colonization was independent of conditions, i.e. pre-treatment media and inoculation duration, based on a Tukey simultaneous test to evaluate significant differences among log reductions (Table 1). Since quantitative results could not be achieved with S. epidermidis after whole blood pre-conditioning, microscopy was conducted to determine whether the Sharklet micropattern would perform in this condition. Micrographs qualitatively demonstrate Sharklet inhibition of S. aureus and S. epidermidis with whole blood pre-conditioning after $18 \mathrm{~h}$ of incubation (Figure 2). An additional Sharklet micropattern $(+3 S K 2 \times 2)$, in which the features protrude from the surface, was qualitatively assessed for performance as an alternative pattern for a CVC application that may be investigated further in future testing. Both micropatterns demonstrated less microbial colonization and smaller aggregates than control surfaces for the two

Table 1 The Sharklet micropattern reduces bacterial colonization after blood protein treatment LD: ANOVA determination of Average LogCFU/50 $\mathrm{mm}^{2}$; SEM: Standard error of the Mean; Conditions that share the same statistical group are not significantly different with $p>0.05$

\begin{tabular}{|c|c|c|c|c|c|c|c|c|}
\hline Organism & Agitation & $\begin{array}{l}\text { Incubation } \\
\text { period (hr) }\end{array}$ & $\begin{array}{l}\text { Pre-condition } \\
\text { media }\end{array}$ & $\begin{array}{l}\text { Unpatterned } \\
\text { LD (SEM) }\end{array}$ & $\begin{array}{l}-3 S K 2 \times 2 \text { LD } \\
\text { (SEM) }\end{array}$ & $\begin{array}{l}\text { Percent } \\
\text { Reduction }\end{array}$ & $p$ value & cpi \\
\hline \multirow[t]{8}{*}{ S. aureus ATCC 6538} & Static & 1 & Saline & $4.05(0.17)$ & $3.17(0.20)$ & $94 \%$ & 0.001 & $A$ \\
\hline & & & Whole Blood & $3.82(0.13)$ & $3.37(0.16)$ & $83 \%$ & 0.003 & A \\
\hline & & 18 & Saline & $4.91(0.25)$ & $3.91(0.21)$ & $89 \%$ & 0.019 & A \\
\hline & & & Whole Blood & $3.71(0.29)$ & $3.23(0.31)$ & $70 \%$ & 0.048 & A \\
\hline & Dynamic & 1 & Saline & $5.23(0.22)$ & $4.79(0.16)$ & $64 \%$ & 0.128 & A \\
\hline & & & Whole Blood & $4.5(0.21)$ & $3.9(0.37)$ & $74 \%$ & 0.128 & A \\
\hline & & 18 & Saline & $5.66(0.1)$ & $4.82(0.19)$ & $85 \%$ & 0.008 & A \\
\hline & & & Whole Blood & $4.49(0.17)$ & $4.06(0.23)$ & $63 \%$ & 0.032 & A \\
\hline \multirow[t]{4}{*}{ S. epidermidis ATCC 35984} & Static & 1 & Saline & $5.04(0.09)$ & $4.23(0.15)$ & $84 \%$ & 0.065 & A \\
\hline & & & $25 \%$ Serum & $3.68(0.08)$ & $3.24(0.12)$ & $64 \%$ & 0.005 & A \\
\hline & & 18 & Saline & $5.06(0.1)$ & $3.92(0.1)$ & $91 \%$ & 0.001 & A \\
\hline & & & $25 \%$ Serum & $3.84(0.09)$ & $3.47(0.12)$ & $71 \%$ & 0.003 & A \\
\hline
\end{tabular}




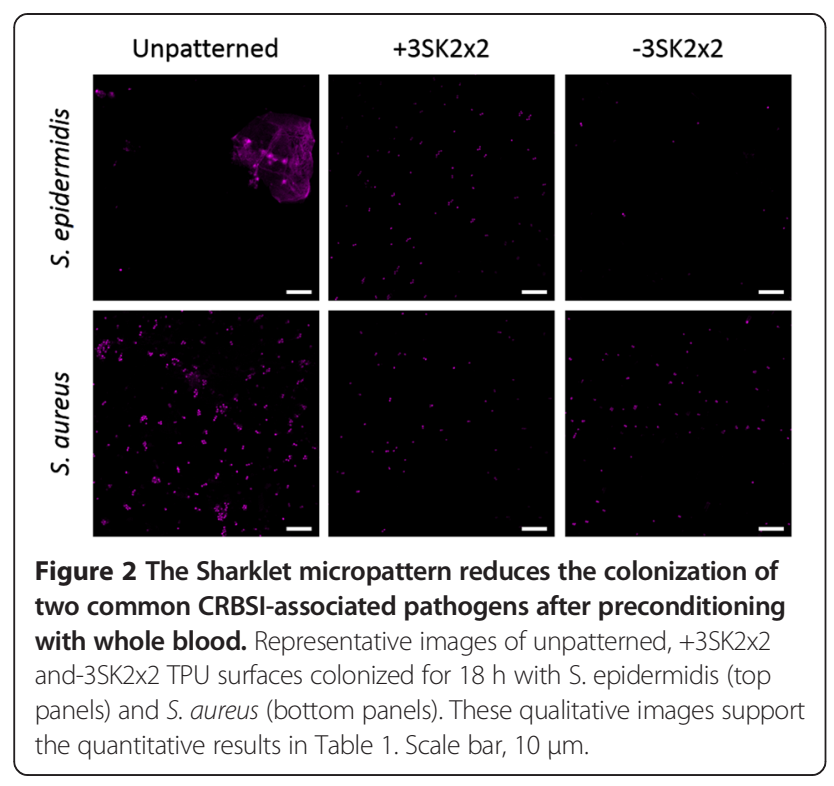

organisms tested (Figure 2). Large S. epidermidis colonies were consistently observed on smooth surfaces (Figure 2).

\section{Platelet adhesion}

The first step to reducing the potential for device associated thrombosis is to reduce the level of platelet adhesion to the device. To investigate the potential of the Sharklet micropattern to influence platelet adhesion, -3 SK $2 \times 2$ and +3 SK $2 \times 2$ TPU surfaces were evaluated. Representative images and quantitative analysis show that these surface modifications demonstrated a $76 \%$ and $86 \%(\mathrm{p}<0.05)$ reduction in platelet area coverage, respectively, when compared to unpatterned TPU controls (Figure 3). The difference in adhesion levels between the two pattern types was not statistically significant $(p=0.21$; Figure $3 d)$.

\section{Fibrin sheath formation}

An ideal blood contacting biomaterial would reduce both platelet adhesion and activation to inhibit thrombotic activity. To determine whether the Sharklet micropattern would influence platelet activation in addition to attachment, fibrin sheath formation was measured as a clinically relevant end-point. The- 3 SK $2 \times 2$ and $+3 S K 2 \times 2$ micropatterns in TPU were evaluated and compared to unpatterned TPU controls. Results show $70 \%$ and $80 \%$ reductions $(\mathrm{p}<0.05)$ in fibrinogen coverage, respectively (Figure 4). The representative images highlight the differences in fibrin strand formation and coverage on the unpatterned TPU surface compared to the distribution of globular fibrinogen on the micropatterned surfaces (Figure 4). The +3 SK $2 \times 2$ micropattern showed significantly lower fibrin sheath coverage than the-3SK $2 \times 2$ micropattern across experiments (Tukey test $p=0.05$, Figure $4 \mathrm{~d}$ ).

\section{Discussion}

Current antimicrobial and heparin coatings used to prevent CRBSI and CRT are limited in their efficacy and are hampered by safety concerns. Micropatterned surfaces have shown promise for reducing bioadhesion in a range of environments and represent a paradigm shift in methods for improving biomaterial compatibility [49-51]. Ordered pillar or well feature configurations have been the primary surface topography evaluated for platelet and bacterial control [30,31,52-58]. However, the Sharklet micropattern has been shown to be the most effective topography for bacterial control with one to three log reductions in microbial attachment across a range of species that cause hospital acquired infections (i.e. Pseudomonas aeruginosa, Staphylococcus aureus, Escherichia coli, Klebsiella pneumoniae, Acinetobacter baumannii) [32-34]. The true clinical effect of the Sharklet micropattern is the focus of future investigations based on the promising results of in vitro studies such as those presented here. The value of the micropattern approach is the potential to limit bacterial load below a clinically-relevant level without killing bacteria, so as to avoid the emergence of resistant strains of bacteria and difficult-to-treat infections.
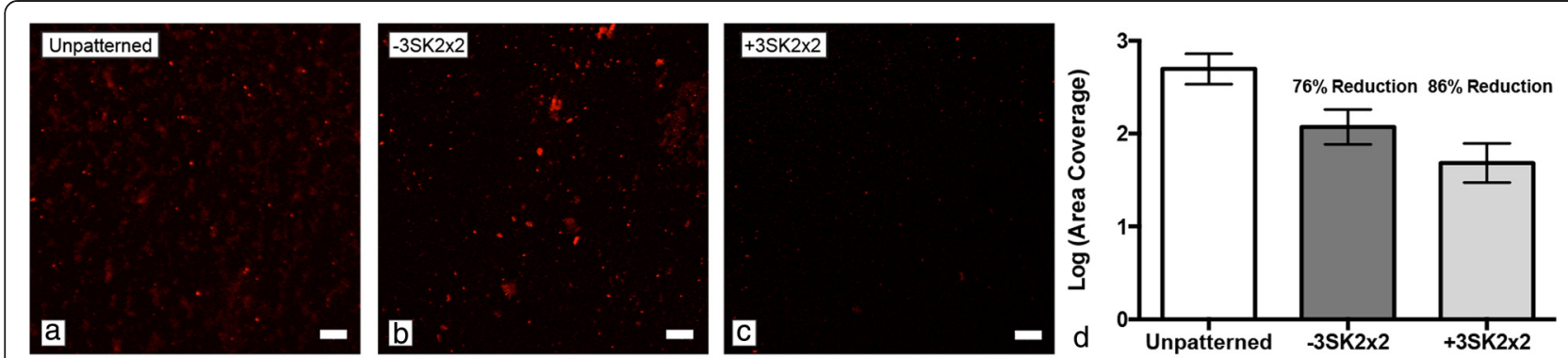

Figure 3 The Sharklet micropattern reduces platelet adhesion. Representative images of immunostained platelets on (a) unpatterned, (b) +3 SK2 22 and (c) -3 SK2 22 TPU surfaces. Quantification of fluorescent images revealed that both Sharklet micropatterns significantly reduce platelet area coverage compared to unpatterned controls. Scale bar, $10 \mu \mathrm{m}$. 

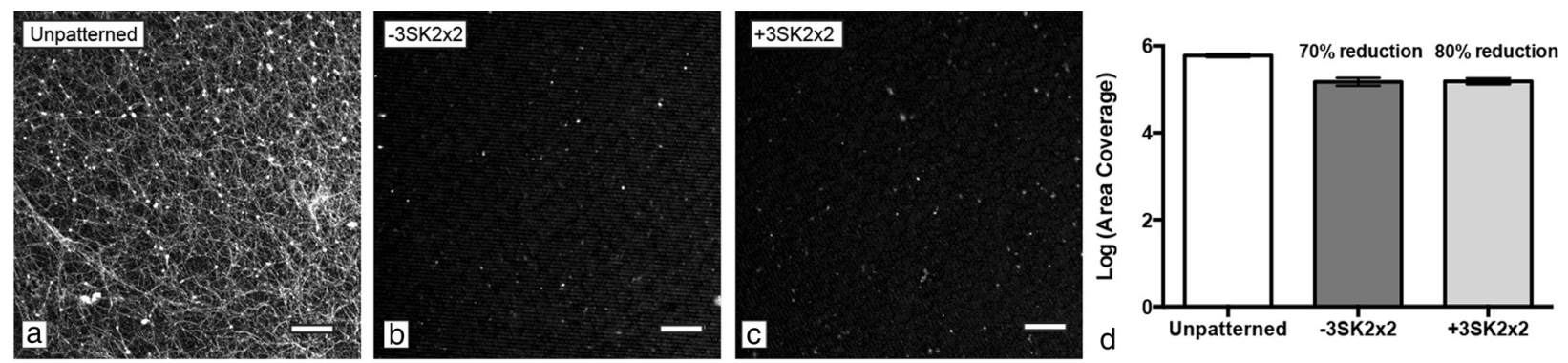

Figure 4 The Sharklet micropattern reduces fibrin sheath formation resulting from platelet activation. Representative images of immunostained fibrinogen on (a) unpatterned, (b) +3 SK $2 \times 2$ and (c) $-3 S K 2 \times 2$ TPU surfaces. Quantification of fluorescent images revealed that both Sharklet micropatterns significantly reduce fibrinogen area coverage compared to unpatterned controls. Scale bar, 50 um.

The Sharklet micropattern has shown promise for controlling bacterial interaction for several medical device applications (e.g. urinary catheter and endotracheal tubes) [32,33], but has yet to be evaluated for effectiveness in a vascular environment and in a TPU material that is predominately used for vascular access devices. This study is the first of its kind to demonstrate the ability for an ordered micropattern, specifically the Sharklet micropattern, to reduce $S$. aureus colonization after exposure to whole blood (Table 1). This study also presents the first ordered micropattern embossed in TPU to show performance against several CVC fouling agents, i.e., bacterial colonization, platelet adhesion and fibrin sheath formation (Figures 2, 3, 4 and Table 1).

This study demonstrates that not only do fewer platelets adhere to the Sharklet micropattern, but there is also significantly less platelet activation resulting in fibrin sheath formation (Figures 3, 4). Complex fibrin networks are a clinically relevant outcome of platelet adhesion and activation, often leading to CVC occlusion or clots that cause thromboembolisms $[14,22]$. These fibrin networks have been shown to facilitate microbial colonization and correlate with CRBSIs that occur in the clinic [20,22,24-27]. This study shows that the Sharklet micropattern can individually reduce bacterial colonization in a simulated vascular environment and reduce fibrin sheath formation that can enhance microbial colonization, thereby functioning through a dual approach to potentially limit infections.

Anti-adhesive or anti-biofilm surface alterations may become competitive anti-infective solutions in the near future as the demand increases for alternative approaches $[59,60]$. Non-wetting topographies, like the Sharklet micropattern, maintain air pockets among features that limit microorganism interaction and provide energetically unstable surfaces for bio-adhesion [37,61]. These surface structures create hydrophobic effects with enhanced liquid pinning/slipping to prevent biofouling [35,62]. For CVC biomaterials, the combined effect of reduced microbial burden (Table 1), smaller microbial aggregates (Figure 2), and reduced fibrin sheath formation (Figure 4) would likely allow for improved immune clearance without the need for multi-log kill effects achieved through antimicrobials.

The Sharklet micropattern with protruding features $(+3 \mathrm{SK} 2 \times 2)$ showed improved performance against platelet adhesion and activation when compared to the micropattern with recessed features $(-3 \mathrm{SK} 2 \times 2)$ (Figures 3, 4). Future work will evaluate feature size and spacing required to achieve optimal boundary layer slip conditions for improved hydrodynamics based on contact line pinning/slipping [63]. It is anticipated that after pattern optimization and manufacturing scale up, a CVC with the Sharklet micropattern will demonstrate reduced CRBSI and CRT rates through preclinical and clinical studies.

\section{Conclusions}

The Sharklet micropattern reduces $S$. aureus and S. epidermidis colonization after exposure to a simulated vascular environment by $70 \%$ or greater $(\mathrm{p}<0.05)$ when compared to smooth unpatterned controls. This micropattern similarly reduces platelet adhesion and fibrin sheath formation by approximately $80 \%(\mathrm{p}<0.05)$. Combined, these results suggest that the Sharklet micropattern implemented onto CVC surfaces will provide clinicians with a non-eluting and non-toxic technology that inhibits the mechanisms that lead to CRBSIs and CRTs.

\section{Abbreviations}

CVC: Central venous catheter; TPU: Thermoplastic polyurethane;

CRBSI: Catheter-related blood stream infection; CRT: Catheter-related thrombosis; TSB: Tryptic soy broth; TSA: Tryptic soy agar; PBS: Phosphate buffered saline; CFU: Colony forming unit; LR: Log reduction.

\section{Competing interests}

The authors declare that they have no competing interests.

\section{Authors' contributions}

RM participated in the design of the study, carrying out the colonization and platelet adhesion assays, statistical analysis, data analysis and interpretation, and drafting the manuscript. CM participated in the design of the study, carrying out the platelet adhesion and fibrin sheath assays, statistical analysis, and data analysis and interpretation. EM participated in the design of the 
study and data interpretation. MD participated in designing and carrying out the fibrin sheath assays. JF participated in designing and carrying out the platelet adhesion assays. CS and AB participated in the design of the study and data interpretation. SR conceived the study, participated in its design and coordination, data interpretation, and helped to draft the manuscript. All authors participated in reviewing and editing the manuscript. All authors read and approved the final manuscript.

\section{Authors' information}

$\mathrm{RM}, \mathrm{CM}, \mathrm{EM}, \mathrm{MD}$ and JF are researchers and SR is the Vice President of Research and Development for Sharklet Technologies, Inc. (STI); CS is a vascular device biomaterials expert and professor at Pennsylvania State University; $A B$ is a materials engineer and professor at the University of Florida, Gainesville and is the inventor of the micro-pattern technology where he continues to consult on the technology for STI.

\section{Acknowledgments}

The authors thank Bryce C. Stevenson and MiKayla M. Henry for fabricating, imaging and characterizing micropatterned samples. This study was supported by NIH/NHLBI Phase I SBIR funding, grant number 1R43HL11241001. Images taken with the Zeiss LSM 510 META on Axiovert $200 \mathrm{M}$ confocal microscope were performed in the University of Colorado Anschutz Medical Campus Advance Light Microscopy Core supported in part by NIH/NCRR Colorado CTSI grant number UL1RR025780.

\section{Author details}

${ }^{1}$ Sharklet Technologies, Inc, 12635 E. Montview Blvd. Suite 155, Aurora CO 80045, CO, USA. ${ }^{2}$ Departments of Bioengineering and Surgery, Pennsylvania State University, Hershey, PA, USA. ${ }^{3}$ Departments of Materials Science and Engineering and Biomedical Engineering University of Florida, Gainesville, FL 32611, USA.

\section{Received: 23 September 2014 Accepted: 27 January 2015}

\section{Published online: 26 February 2015}

\section{References}

1. Darouiche RO. Prevention of infections associated with vascular catheters. Int J Artif Organs. 2008;31(9):810-9.

2. Lin WC, Yu DG, Yang MC. Blood compatibility of thermoplastic polyurethane membrane immobilized with water-soluble chitosan/dextran sulfate. Colloids Surf B: Biointerfaces. 2005;44(2-3):82-92. doi:10.1016/j. colsurfb.2005.05.015.

3. Burns KE, McLaren A. A critical review of thromboembolic complications associated with central venous catheters. Canadian journal of anaesthesia= Journal canadien d'anesthesie. 2008;55(8):532-41. doi:10.1007/BF03016674.

4. Pittet D, Tarara D, Wenzel RP. Nosocomial bloodstream infection in critically ill patients. Excess length of stay, extra costs, and attributable mortality. JAMA. 1994;271(20):1598-601.

5. Weber DJ, Rutala WA. Central line-associated bloodstream infections: prevention and management. Infect Dis Clin North Am. 2011;25(1):77-102. doi:10.1016/j.idc.2010.11.012.

6. Maki DG, Kluger DM, Crnich CJ. The risk of bloodstream infection in adults with different intravascular devices: a systematic review of 200 published prospective studies. Mayo Clin Proc. 2006;81(9):1159-71. doi:10.4065/81.9.1159.

7. O'Grady NP, Alexander M, Dellinger EP, Gerberding JL, Heard SO, Maki DG, et al. Guidelines for the prevention of intravascular catheter-related infections. Infection control and hospital epidemiology : the official journal of the Society of Hospital Epidemiologists of America. 2002;23(12):759-69. doi:10.1086/502007.

8. Hockenhull JC, Dwan K, Boland A, Smith G, Bagust A, Dundar Y, et al. The clinical effectiveness and cost-effectiveness of central venous catheters treated with anti-infective agents in preventing bloodstream infections: a systematic review and economic evaluation. Health Technol Assess. 2008;12(12):ii-v. xi-xii, 1-154.

9. Novikov A, Lam MY, Mermel LA, Casey AL, Elliott TS, Nightingale P. Impact of catheter antimicrobial coating on species-specific risk of catheter colonization: a meta-analysis. Antimicrobial resistance and infection control. 2012;1(1):40. doi:10.1186/2047-2994-1-40

10. Tanwar J, Das S, Fatima Z, Hameed S. Multidrug resistance: an emerging crisis. Interdisciplinary perspectives on infectious diseases. 2014;2014:541340. doi:10.1155/2014/541340
11. Silver S. Bacterial silver resistance: molecular biology and uses and misuses of silver compounds. FEMS Microbiol Rev. 2003;27(2-3):341-53.

12. Al LJaS. Thrombosis and hemorrhage. Third ed. Baltimore, MD: Lippincott Williams and Wilkins; 2002.

13. Gorbet MB, Sefton MV. Biomaterial-associated thrombosis: roles of coagulation factors, complement, platelets and leukocytes. Biomaterials. 2004;25(26):5681-703. doi:10.1016/j.biomaterials.2004.01.023.

14. Linnemann B, Lindhoff-Last E. Risk factors, management and primary prevention of thrombotic complications related to the use of central venous catheters. VASA Zeitschrift fur Gefasskrankheiten. 2012;41(5):319-32. doi:10.1024/0301-1526/a000217.

15. Levine M, Kakkar AK. Catheter-associated thrombosis: thromboprophylaxis or not? Journal of clinical oncology: official journal of the American Society of Clinical Oncology. 2005;23(18):4006-8. doi:10.1200/JCO.2005.12.901.

16. Chong BH. Heparin-induced thrombocytopenia. Journal of thrombosis and haemostasis : JTH. 2003;1(7):1471-8.

17. Rosovsky RP, Kuter DJ. Catheter-related thrombosis in cancer patients: pathophysiology, diagnosis, and management. Hematol Oncol Clin North Am. 2005;19(1):183-202. doi:10.1016/j.hoc.2004.09.007.

18. Raad II, Luna M, Khalil SA, Costerton JW, Lam C, Bodey GP. The relationship between the thrombotic and infectious complications of central venous catheters. JAMA. 1994;271(13):1014-6.

19. Van Rooden CJ, Schippers EF, Barge RM, Rosendaal FR, Guiot HF, Van derMeer FJ, et al. Infectious complications of central venous catheters increase the risk of catheter-related thrombosis in hematology patients: a prospective study. Journal of clinical oncology : official journal of the American Society of Clinical Oncology. 2005;23(12):2655-60. doi:10.1200/JCO.2005.05.002.

20. Lordick F, Hentrich M, Decker T, Hennig M, Pohlmann H, Hartenstein R, et al. Ultrasound screening for internal jugular vein thrombosis aids the detection of central venous catheter-related infections in patients with haematooncological diseases: a prospective observational study. Br J Haematol. 2003;120(6):1073-8.

21. Del Principe MI, Buccisano F, Maurillo L, Venditti D, Cefalo M, Sarlo C, et al. Infections increase the risk of central venous catheter-related thrombosis in adult acute myeloid leukemia. Thromb Res. 2013;132(5):511-4. doi:10.1016/j. thromres.2013.08.007.

22. Rowan CM, Miller KE, Beardsley AL, Ahmed SS, Rojas LA, Hedlund TL, et al. Alteplase use for malfunctioning central venous catheters correlates with catheter-associated bloodstream infections. Pediatric critical care medicine : a journal of the Society of Critical Care Medicine and the World Federation of Pediatric Intensive and Critical Care Societies. 2013;14(3):306-9. doi:10.1097/PCC.0b013e318271f48a.

23. Timsit JF, Farkas JC, Boyer JM, Martin JB, Misset B, Renaud B, et al. Central vein catheter-related thrombosis in intensive care patients: incidence, risks factors, and relationship with catheter-related sepsis. Chest. 1998;114(1):207-13.

24. Mehall JR, Saltzman DA, Jackson RJ, Smith SD. Fibrin sheath enhances central venous catheter infection. Crit Care Med. 2002;30(4):908-12.

25. Vaudaux P, Pittet D, Haeberli A, Huggler E, Nydegger UE, Lew DP, et al. Host factors selectively increase staphylococcal adherence on inserted catheters: a role for fibronectin and fibrinogen or fibrin. J Infect Dis. 1989;160(5):865-75.

26. Keller JE, Hindman JW, Mehall JR, Smith SD. Enoxaparin inhibits fibrin sheath formation and decreases central venous catheter colonization following bacteremic challenge. Crit Care Med. 2006;34(5):1450-5. doi:10.1097/01. CCM.0000215832.40827.71

27. Herrmann M, Vaudaux PE, Pittet D, Auckenthaler R, Lew PD, SchumacherPerdreau F, et al. Fibronectin, fibrinogen, and laminin act as mediators of adherence of clinical staphylococcal isolates to foreign material. J Infect Dis. 1988;158(4):693-701.

28. Kastrup CJ, Boedicker JQ, Pomerantsev AP, Moayeri M, Bian Y, Pompano RR, et al. Spatial localization of bacteria controls coagulation of human blood by 'quorum acting'. Nat Chem Biol. 2008;4(12):742-50.

29. Levi M, Keller TT, Van Gorp E, Ten Cate H. Infection and inflammation and the coagulation system. Cardiovasc Res. 2003;60(1):26-39.

30. Koh LB, Rodriguez I, Venkatraman SS. The effect of topography of polymer surfaces on platelet adhesion. Biomaterials. 2010;31(7):1533-45. doi:10.1016/j. biomaterials.2009.11.022.

31. Milner KR, Snyder AJ, Siedlecki CA. Sub-micron texturing for reducing platelet adhesion to polyurethane biomaterials. J Biomed Mater Res A. 2006;76(3):561-70. doi:10.1002/jbm.a.30554.

32. May RM, Hoffman MG, Sogo MJ, Parker AE, OToole GA, Brennan AB, et al. Micro-patterned surfaces reduce bacterial colonization and biofilm 
formation in vitro: Potential for enhancing endotracheal tube designs. Clinical and translational medicine. 2014;3:8. doi:10.1186/2001-1326-3-8.

33. Reddy ST, Chung KK, McDaniel CJ, Darouiche RO, Landman J, Brennan AB. Micropatterned surfaces for reducing the risk of catheter-associated urinary tract infection: an in vitro study on the effect of sharklet micropatterned surfaces to inhibit bacterial colonization and migration of uropathogenic Escherichia coli. Journal of endourology/Endourological Society. 2011:25(9):1547-52. doi:10.1089/end.2010.0611.

34. Chung KK, Schumacher JF, Sampson EM, Burne RA, Antonelli PJ, Brennan AB. Impact of engineered surface microtopography on biofilm formation of Staphylococcus aureus. Biointerphases. 2007;2(2):89-94. doi:10.1116/1.2751405.

35. Carman ML, Estes TG, Feinberg AW, Schumacher JF, Wilkerson W, Wilson LH, et al. Engineered antifouling microtopographies-correlating wettability with cell attachment. Biofouling. 2006;22(1-2):11-21. doi:10.1080/ 08927010500484854

36. Schumacher JF, Carman ML, Estes TG, Feinberg AW, Wilson LH, Callow ME, et al. Engineered antifouling microtopographies-effect of feature size, geometry, and roughness on settlement of zoospores of the green alga Ulva. Biofouling. 2007;23(1-2):55-62. doi:10.1080/08927010601136957.

37. Schumacher JF, Long CJ, Callow ME, Finlay JA, Callow JA, Brennan AB. Engineered nanoforce gradients for inhibition of settlement (attachment) of swimming algal spores. Langmuir : the ACS journal of surfaces and colloids. 2008;24(9):4931-7. doi:10.1021/la703421v.

38. Clawson CC, White JG. Platelet interaction with bacteria. II. Fate of the bacteria. Am J Pathol. 1971;65(2):381-97.

39. Tomlinson S, Taylor PW, Morgan BP, Luzio JP. Killing of gram-negative bacteria by complement. Fractionation of cell membranes after complement C5b-9 deposition on to the surface of Salmonella minnesota Re595. Biochem J. 1989;263(2):505-11.

40. Martin $\mathrm{E}$, Bhakdi S. Flow cytometric assay for quantifying opsonophagocytosis and killing of Staphylococcus aureus by peripheral blood leukocytes. J Clin Microbiol. 1992;30(9):2246-55.

41. Kerrigan SW, Clarke N, Loughman A, Meade G, Foster TJ, Cox D. Molecular basis for Staphylococcus aureus-mediated platelet aggregate formation under arterial shear in vitro. Arterioscler, Thromb, Vasc Biol. 2008;28(2):335-40. doi:10.1161/ATVBAHA.107.152058.

42. Appelgren P, Ransjo U, Bindslev L, Espersen F, Larm O. Surface heparinization of central venous catheters reduces microbial colonization in vitro and in vivo: results from a prospective, randomized trial. Crit Care Med. 1996;24(9):1482-9.

43. Malaty J, Antonelli PJ. Effect of blood and mucus on tympanostomy tube biofilm formation. Laryngoscope. 2008;118(5):867-70. doi:10.1097/ MLG.0b013e3181671b02.

44. Murga R, Miller JM, Donlan RM. Biofilm formation by gram-negative bacteria on central venous catheter connectors: effect of conditioning films in a laboratory model. J Clin Microbiol. 2001;39(6):2294-7. doi:10.1128/JCM. 39.6.2294-2297.2001.

45. Nifong TP, McDevitt TJ. The effect of catheter to vein ratio on blood flow rates in a simulated model of peripherally inserted central venous catheters. Chest. 2011;140(1):48-53. doi:10.1378/chest. 10-2637.

46. Hamilton MA, Hamilton GC, Goeres DM, Parker AE. Guidelines for the statistical analysis of a collaborative study of a laboratory method for testing disinfectant product performance. J AOAC Int. 2013;96(5):1138-51.

47. Muller E, Takeda S, Goldmann DA, Pier GB. Blood proteins do not promote adherence of coagulase-negative staphylococci to biomaterials. Infect Immun. 1991;59(9):3323-6.

48. Crawford RJ, Webb HK, Truong VK, Hasan J, Ivanova EP. Surface topographical factors influencing bacterial attachment. Adv Colloid Interface Sci. 2012;179-182:142-9. doi:10.1016/j.cis.2012.06.015.

49. Chen L, Han D, Jiang L. On improving blood compatibility: from bioinspired to synthetic design and fabrication of biointerfacial topography at micro/ nano scales. Colloids Surf B: Biointerfaces. 2011;85(1):2-7. doi:10.1016/j. colsurfb.2010.10.034.

50. Curtis A, Wilkinson C. Topographical control of cells. Biomaterials. 1997;18(24):1573-83.

51. Xu LC, Siedlecki CA. Submicron-textured biomaterial surface reduces staphylococcal bacterial adhesion and biofilm formation. Acta Biomater. 2012;8(1):72-81. doi:10.1016/j.actbio.2011.08.009.

52. Sandmann R, Henriques SS, Rehfeldt F, Koster S. Micro-topography influences blood platelet spreading. Soft Matter. 2014;10(14):2365-71. doi:10.1039/c3sm52636d
53. Chen H, Song W, Zhou F, Wu Z, Huang H, Zhang J, et al. The effect of surface microtopography of poly(dimethylsiloxane) on protein adsorption, platelet and cell adhesion. Colloids Surf B: Biointerfaces. 2009;71(2):275-81. doi:10.1016/j.colsurfb.2009.02.018.

54. Ding Y, Leng Y, Huang N, Yang P, Lu X, Ge X, et al. Effects of microtopographic patterns on platelet adhesion and activation on titanium oxide surfaces. J Biomed Mater Res A. 2013;101(3):622-32. doi:10.1002/jbm. a.34361.

55. Ge X, Leng Y, Lu X, Ren F, Wang K, Ding Y et al. Bacterial responses to periodic micropillar array. Journal of biomedical materials research Part A. 2014. doi:10.1002/jbm.a.35182

56. Perera-Costa D, Bruque JM, Gonzalez-Martin ML, Gomez-Garcia AC, VadilloRodriguez V. Studying the influence of surface topography on bacterial adhesion using spatially organized microtopographic surface patterns. Langmuir : the ACS journal of surfaces and colloids. 2014;30(16):4633-41. doi:10.1021/la5001057.

57. Hsu LC, Fang J, Borca-Tasciuc DA, Worobo RW, Moraru Cl. Effect of micro-and nanoscale topography on the adhesion of bacterial cells to solid surfaces. Appl Environ Microbiol. 2013;79(8):2703-12. doi:10.1128/AEM. 03436-12.

58. Campoccia D, Montanaro L, Arciola CR. A review of the clinical implications of anti-infective biomaterials and infection-resistant surfaces. Biomaterials. 2013;34(33):8018-29. doi:10.1016/j.biomaterials.2013.07.048.

59. Campoccia D, Montanaro L, Arciola CR. A review of the biomaterials technologies for infection-resistant surfaces. Biomaterials. 2013;34(34):8533-54. doi:10.1016/j.biomaterials.2013.07.089.

60. Decker JT, Kirschner CM, Long CJ, Finlay JA, Callow ME, Callow JA, et al. Engineered antifouling microtopographies: an energetic model that predicts cell attachment. Langmuir: the ACS journal of surfaces and colloids. 2013;29(42):13023-30. doi:10.1021/la402952u.

61. Long CJ, Schumacher JF, Brennan AB. Potential for tunable static and dynamic contact angle anisotropy on gradient microscale patterned topographies. Langmuir: the ACS journal of surfaces and colloids. 2009;25 (22):12982-9. doi:10.1021/la901836w.

62. Reddy ST, Schunk PR, T. BR. Dynamics of low capillary number interfaces moving through sharp features. Physics of Fluids. 2005;17(12).

\section{Submit your manuscript to a SpringerOpen ${ }^{\circ}$ journal and benefit from:}

- Convenient online submission

Rigorous peer review

- Immediate publication on acceptance

- Open access: articles freely available online

- High visibility within the field

- Retaining the copyright to your article

Submit your next manuscript at $>$ springeropen.com 